\title{
The measurement of exchangeable pools of zinc using the stable isotope ${ }^{70} \mathrm{Zn}$
}

\author{
BY SUSAN J. FAIRWEATHER-TAIT ${ }^{1}$, MALCOLM J. JACKSON ${ }^{2}$, \\ THOMAS E. FOX ${ }^{1}$, S. GABRIELLE WHARF ${ }^{1}$, JOHN EAGLES ${ }^{1}$ \\ AND PETER C. CROGHAN ${ }^{3}$ \\ ${ }^{1}$ AFRC Institute of Food Research, Norwich Laboratory, Norwich Research Park, Colney, \\ Norwich NR4 7 UA \\ ${ }^{2}$ Department of Medicine, University of Liverpool, Liverpool L69 $3 B X$ \\ ${ }^{3}$ School of Biological Sciences, University of East Anglia, Norwich NR4 7TJ
}

(Received 3 June 1992 - Accepted 7 September 1992)

\begin{abstract}
The present study was designed to assess the feasibility of using small doses of a stable isotope of $\mathrm{Zn}$ to follow plasma kinetics over a $10 \mathrm{~d}$ period and, hence, make deductions about $\mathrm{Zn}$ turnover and body pool sizes. At the beginning of the $10 \mathrm{~d}$ metabolic balance, two adults, consuming their habitual diet, were given an intravenous injection of ${ }^{70} \mathrm{Zn}$. There was a fourfold difference in the administered dose between the two subjects $(0.445$ and $2.078 \mathrm{mg}$ ). Blood samples were taken at regular intervals and plasma enrichment with ${ }^{70} \mathrm{Zn}$ measured by thermal ionization mass spectrometry. Urine and faeces were collected and analysed for $\mathrm{Zn}$ and ${ }^{70} \mathrm{Zn}$. Kinetic analysis of the plasma ${ }^{70} \mathrm{Zn}$ decay by several different methods was undertaken. It was apparent from both deconvolution analysis of the short-term (0-90 min) decay data and four-compartment modelling of the longer-term (0-24 h) data that isotopic $\mathrm{Zn}$ very rapidly equilibrates with the plasma $\mathrm{Zn}$ and with a rapidly exchanging non-plasma pool, probably located within the liver. This latter pool appears to contain less than $10 \mathrm{mg} \mathrm{Zn}$ and the peak of isotope enrichment occurs at about $20 \mathrm{~min}$ post injection. The later decay of plasma $\mathrm{Zn}$ enrichment appears to be dictated by exchange with a much larger pool of approximate size $350 \mathrm{mg}$.
\end{abstract}

Exchangeable zinc pools: Stable isotopes: Human subjects: Zinc

$\mathrm{Zn}$ requirements for optimal health and function have not been clearly established, primarily because of the difficulties associated with assessing body $\mathrm{Zn}$ status and relating it to dietary intake (Gibson, 1989). Tissue levels fall with $\mathrm{Zn}$ depletion, but at the same time homeostatic mechanisms come into play maintaining the $\mathrm{Zn}$ concentration of important functional pools at the expense of other less critical tissues. For example, in severe $\mathrm{Zn}$ deficiency muscle catabolism takes place, releasing $\mathrm{Zn}$ for systemic redistribution, which explains the reports of normal plasma $\mathrm{Zn}$ concentrations in grossly deficient states such as acrodermatitis enteropathica (Garretts \& Molokhia, 1977). The biological half-life of $\mathrm{Zn}$ in tissues depends to a great extent on the turnover of the tissue itself (Aggett, 1991); thus, the $\mathrm{Zn}$ content of tissues with a relatively slow turnover such as muscle and bone will be less informative about acute changes in $\mathrm{Zn}$ supply than tissues with a shorter half-life such as platelets. Even if the key components of the body which are useful indicators of $\mathrm{Zn}$ status are identified their $\mathrm{Zn}$ content may not necessarily give a true representation of how wellnourished the body is with respect to Zn (Jackson, 1989).

A potential approach to the study of relationships between dietary $\mathrm{Zn}$ supply and body status is the measurement of plasma $\mathrm{Zn}$ kinetics following an intravenous injection of a $\mathrm{Zn}$ isotope. Detailed studies of $\mathrm{Zn}$ metabolism have been carried out using ${ }^{65} \mathrm{Zn}$ in man 
(Wastney et al. 1986) and rats (Lowe et al. 1991), and preliminary reports describe the feasibility of using stable isotopes to study Zn kinetics (Turnlund \& Keyes, 1990; Miller et al. 1991; Lowe et al. 1992). Stable isotopes offer a clear advantage over radioisotopes in that there are no ethical problems with administering them, even to the most vulnerable groups. The present paper presents the results of a preliminary study investigating the methodology for carrying out kinetic analysis of $\mathrm{Zn}$ metabolism using the stable isotope ${ }^{70} \mathrm{Zn}$.

\title{
MATERIALS AND METHODS
}

A metabolic study was performed over a $10 \mathrm{~d}$ period in which $\mathrm{Zn}$ intake and excretion were measured. During this time plasma $\mathrm{Zn}$ kinetics were investigated following an intravenous dose of the stable isotope ${ }^{70} \mathrm{Zn}$.

\section{Subjects}

Two subjects, one male (M) and one female (F), volunteered for the study, which was approved by the Institute of Food Research Ethics Committee. The age, height and unclothed weight of subjects $M$ and $F$ were 33 and 41 years, 1.705 and $1.630 \mathrm{~m}$, and 62.5 and $62.0 \mathrm{~kg}$ respectively.

\begin{abstract}
Diets
Duplicate diet collections were carried out $2 \mathrm{~d}$ before the start of the study, in order to familiarize subjects with the routine, and for a further $10 \mathrm{~d}$ during the course of the metabolic study. Subjects were very careful to maintain their usual dietary practices in order not to perturb $\mathrm{Zn}$ metabolism in any way. All food and drink consumed each day was prepared and weighed out in duplicate. Solid material for each day was collected in a large plastic bag, and liquids in an acid-washed polypropylene container. Each day's collection was weighed and homogenized in a Waring blender (Jennings, Nottingham), and subsamples taken and stored at $-18^{\circ}$ before freeze-drying. The freeze-dried material was pulverized and remixed by hand in a plastic bag and analysed for $\mathrm{Zn}$ by atomic absorption spectroscopy (AAS) as described previously (Fairweather-Tait et al. 1992). Energy was measured from heats of combustion of $0.5-1.0 \mathrm{~g}$ dry diet in a Gallenkamp adiabatic bomb calorimeter (Gallenkamp, Loughborough) using benzoic acid thermochemical standard. Protein was determined using the Kjeldahl method.
\end{abstract}

\section{Isotope administration}

Subjects were given an intravenous injection of an enriched solution of ${ }^{70} \mathrm{Zn}$ at 09.00 hours after an overnight fast. The isotope was prepared as zinc citrate from ${ }^{70} \mathrm{Zn}$-enriched $\mathrm{ZnO}$ (65.51 atom \%, Oak Ridge National Laboratory, TN, USA) as described previously (Fairweather-Tait et al. 1992), and administered through a venous catheter (Butterfly-21; Abbott Ireland). The doses of ${ }^{70} \mathrm{Zn}$-enriched $\mathrm{Zn}$ were $2.078 \mathrm{mg}(\mathrm{M})$ and $0.445 \mathrm{mg}(\mathrm{F})$. A light breakfast was consumed $2 \mathrm{~h}$ after the injection, together with $500 \mathrm{mg}$ carmine to mark the beginning of the metabolic balance. Carmine was taken $10 \mathrm{~d}$ later to mark the end of the balance.

\section{Collection of samples}

Blood samples $(5 \mathrm{ml})$ were taken through the catheter just before and 2, 5, 10, 20, 30, 45, 60,90 and 120 min post-injection, and at 3,4, 5, 6, 9, 12, 15, 18, 21 and $24 \mathrm{~h}$, and daily for a further $9 \mathrm{~d}$. Blood was collected in coated Li-heparin tubes. After removal of blood, the catheter was flushed with saline $(9 \mathrm{~g} \mathrm{NaCl} / 1)$ to keep it patent. However, it became blocked in subject M $12 \mathrm{~h}$ after insertion, and further blood samples were obtained by venepuncture using veins in the ankle and arm. In subject $\mathrm{F}$ blood was obtained via the catheter for $3 \mathrm{~d}$, 
and then from veins in the ankle and arm. The blood was centrifuged at $3000 \mathrm{rev} . / \mathrm{min}$ for $5 \mathrm{~min}$, and the plasma removed and stored at $-18^{\circ}$ until analysis. This was performed as soon as possible after removal from the body but during the night this was not possible so the blood was stored at $4^{\circ}$ until it could be centrifuged.

Complete urine collections were made for each $24 \mathrm{~h}$ period, commencing immediately after first emptying the bladder in the morning. All containers used for collections were acid-washed. Faeces were collected from the morning of the injection until the disappearance of the second carmine marker; stools were passed directly into plastic bags for individual analysis.

\section{Analysis of samples}

(a) $A A S$. Faecal collections were pooled for each $24 \mathrm{~h}$ period, autoclaved, freeze-dried, ground in a coffee grinder, and mixed in a powder mixer for $30 \mathrm{~min}$. Portions of about $3 \mathrm{~g}$ were taken and heated in a muffle furnace in silica crucibles to $480^{\circ}$ for $48 \mathrm{~h}$. The resultant ash was mixed and a subsample dissolved in hot concentrated $\mathrm{HCl}$ (AR grade), made up to an appropriate volume with distilled water and analysed for $\mathrm{Zn}$ by flame AAS (Philips PU9000, Cambridge), together with NBS reference materials (Office of Standard Reference Materials, Gaithersburg, MD, USA).

The urine was deproteinized by adding $1 \mathrm{ml}$ concentrated $\mathrm{HCl}$ (AR grade) to $9 \mathrm{ml}$ urine, filtered through Whatman 542 filter paper and the filtrate analysed directly for Zn by AAS as described previously.

(b) Thermal ionization mass spectrometry (TIMS). Portions of ashed faeces $(0 \cdot 15 \mathrm{~g})$ were dissolved in $2 \mathrm{ml} \mathrm{HCl}$ ('aristar' grade) and $8 \mathrm{ml}$ quartz-distilled water added. The solution was applied to a glass column of AG 1-X8 anion-exchange resin, 200-400 mesh, chloride form (Bio Rad Laboratories, Richmond, CA, USA) to extract selectively the Zn (Fox et al. 1991). The tenth $1.5 \mathrm{ml}$ fraction was taken for TIMS analysis (THQ; FinneganMATGmbH, Bremen, Germany; Eagles et al. 1989).

Plasma and urine were digested with concentrated $\mathrm{HNO}_{3}$ ('aristar' grade) in a microwave oven (MDS-81D; CEM Corporation, Matthews, NC, USA) in pressurized teflon vessels. The volumes used were $1 \mathrm{ml}$ plasma plus $5 \mathrm{ml}$ acid, and $5 \mathrm{ml} 5$-fold concentrated urine plus $10 \mathrm{ml}$ acid, with a heating time of approximately 20 min per twelve samples (sequence: $50 \%$ power for $30 \mathrm{~s}, 100 \%$ power for $4 \mathrm{~min}$, cool and release gases, $100 \%$ power for $4 \mathrm{~min}$, and $50 \%$ power for $12-16 \mathrm{~min}$ ). The resultant solutions were evaporated, the residue dissolved in $2 \mathrm{ml}$ concentrated $\mathrm{HCl}$ ('aristar' grade), $8 \mathrm{ml}$ quartzdistilled water added and the $\mathrm{Zn}$ extracted by anion-exchange using plastic polypropylene columns. The third $1.5 \mathrm{ml}$ fraction was taken for TIMS analysis.

(c) Estimation of zinc from dose. The proportion of the dose in plasma, urine or faeces was derived from mass spectrometric isotopic ratios using simultaneous equations. In the case of plasma samples, the total $\mathrm{Zn}$ content was also determined by using a spike of ${ }^{68} \mathrm{Zn}$ of known mass. The molar fractions were defined as $\alpha$ from the intravenous dose, $\beta$ from the spike and $(1-(\alpha+\beta))$ from the body. Equations were derived for each measured isotopic ratio to calculate the proportion of the dose present in the sample.

\section{Nomenclature of zinc 'pools'}

Because of the different methods previously used to examine putative $\mathrm{Zn}$ pools in man (Foster et al. 1979; Jackson et al. 1988; Johnson et al. 1991; Miller et al. 1991) and the variable nature of the analyses which can be applied to isotopic decay data, it is not possible to devise a system of nomenclature which will be adequate for all situations. However, we propose that since most isotopic techniques will involve a time dimension over which turnover is studied then this should be included in the nomenclature. Thus, the composite 


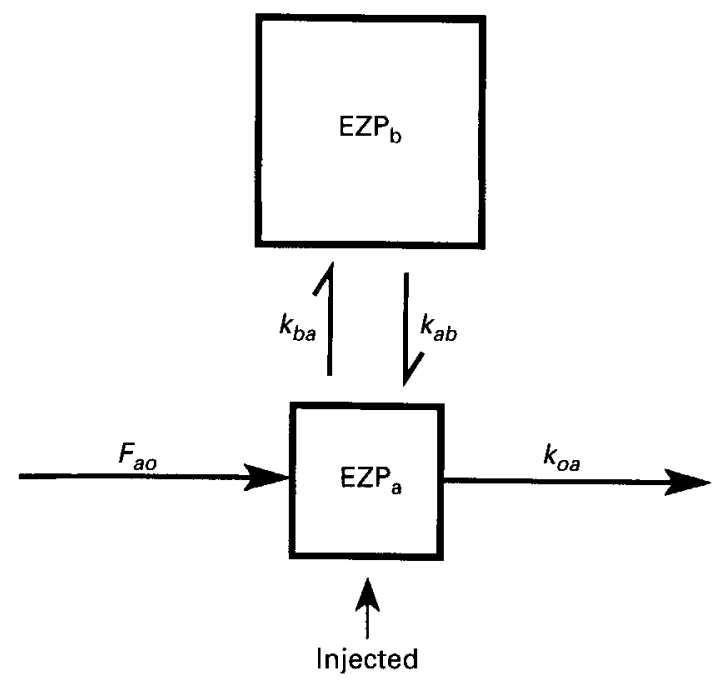

Fig. 1. Two-compartment model for zinc pools in man and rate-constants $(k)$, where $\mathrm{EZP}_{\mathrm{a}}$ is the plasma pool, $\mathrm{EZP}_{\mathfrak{b}}$ is the rapidly exchangeable pool, and $\mathrm{F}$ is the flux into the system.

pool described here from isotopic data from 1-9 d post-injection should be described as exchangeable Zn pool, 1-9 d (EZP (1-9 d)). Thus, if future workers decide that this 'pool' can be realistically subdivided into, for instance, EZP (1-3 d) and EZP (3-9 d) this would not be inconsistent with current data. Where a time dimension of study is not relevant or possible to define, such as in the two rapidly exchanging pools described by the twocompartment model (Fig. 1), we propose that the current alphabetical nomenclature in order of deconvolution should continue but with the designation EZP. Thus, the first pool with which injected $\mathrm{Zn}$ equilibrates (primarily plasma pool) will be $\mathrm{EZP}_{\mathrm{a}}$ (the size of this pool with be Qa) and the second, putative liver pool, will be EZP ${ }_{b}$.

Thus, EZP (1-9 d) is a composite pool which dictates isotopic kinetics over this period of time, which will be composed of $\mathrm{EZP}_{\mathrm{a}}, \mathrm{EZP}_{\mathrm{b}}$ etc. It is hoped that such a systematic nomenclature will permit comparison between publications and prevent the use of terms such as 'rapid' or 'slowly' exchanging pools which are relative to the period of observation and not useful for nomenclature.

\section{Analysis of isotope data}

(a) Two-compartment model ( 090 min post-injection). The plasma ${ }^{70} \mathrm{Zn}$ decay over $90 \mathrm{~min}$ was analysed using the techniques described by Shipley \& Clark (1972). In common with previous studies using ${ }^{65} \mathrm{Zn}$ in rats (Lowe et al. 1991) and ${ }^{70} \mathrm{Zn}$ in man (Lowe et al. 1992), the decay over this period of time was found to obey closely two-compartment kinetics. The 'best-fit' double-exponential equation describing the two-component curve was obtained by analysis of data using a computer program for fitting non-linear functions ('Regression'; Labtools, Blackwell Scientific Software, Oxford). The size of the two exchangeable pools contributing to the observed kinetics $\left(\mathrm{EZP}_{\mathrm{a}}\right.$ and $\left.\mathrm{EZP} \mathrm{P}_{\mathrm{b}}\right)$, their fractional turnover rates and the fluxes between these pools were calculated from the amount of ${ }^{70} \mathrm{Zn}$ injected and the decay equation as described by Shipley \& Clark (1972), assuming that on injection the ${ }^{70} \mathrm{Zn}$ rapidly equilibrated with all the $\mathrm{Zn}$ present in plasma (Lowe et al. 1991).

(b) Four-compartment model $(0-24 \mathrm{~h}$ post-injection). A four-compartment model involving gut, plasma, fast and slow tissue compartments was developed (Fig. 2). The fluxes between the compartments are described in terms of differential equations (Appendix). The 


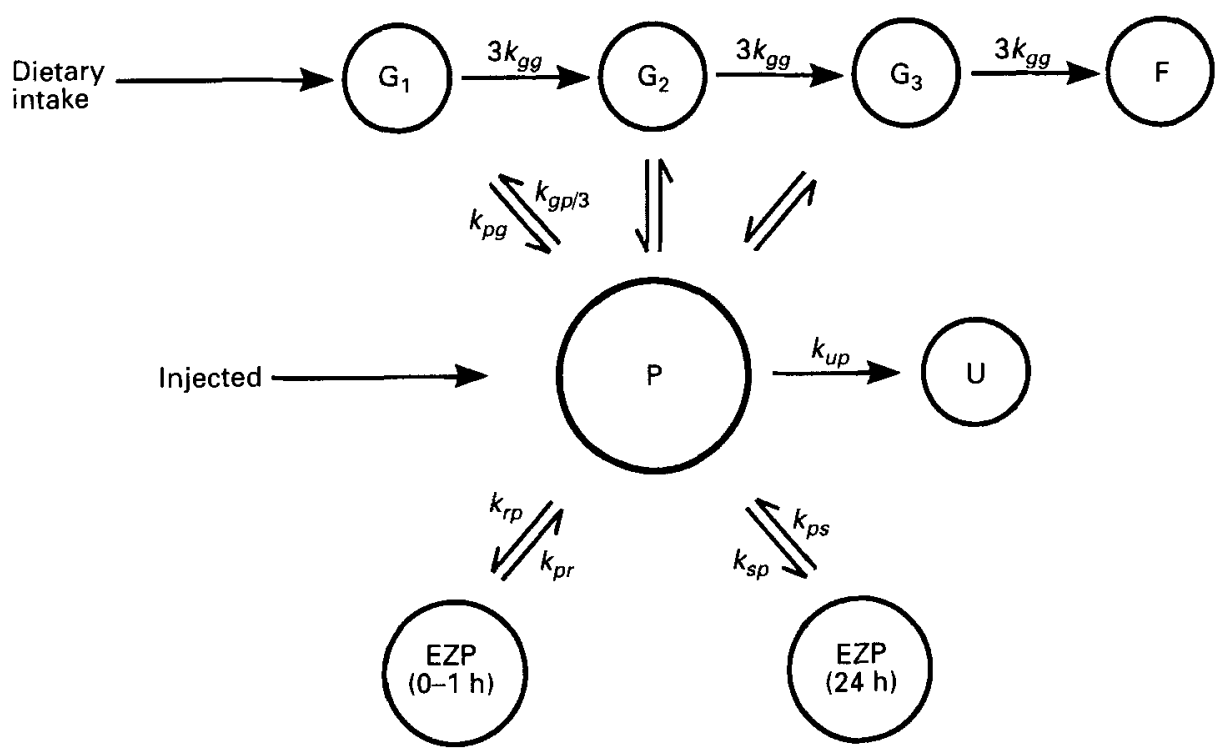

Fig. 2. Four-compartment model for zinc pools in man and rate-constants, where $G$ is gut, $F$ is faecal excretion, $\mathrm{P}$ is plasma, $\mathrm{U}$ is urinary excretion, EZP $(0-1 \mathrm{~h})$ is rapidly exchangeable pool, EZP $(24 \mathrm{~h})$ is slowly exchangeable pool, $k$ are rate-constants defining fluxes between them.

simultaneous solutions of these equations were computed and optimized to the ${ }^{70} \mathrm{Zn}$ data. The procedure is similar to that of Tomlinson et al. (1991). The size of the rapidly exchangeable (EZP $(0-1 \mathrm{~h}))$ and slowly exchangeable (EZP $(24 \mathrm{~h}))$ pools were calculated from rate-constants and an estimate of total plasma $\mathrm{Zn}(\mathrm{P})$. Thus, EZP $(0-1 \mathrm{~h})(\mathrm{mg})$ was $k_{r p} / k_{p r} \times \mathrm{P}$, and EZP $(24 \mathrm{~h})(\mathrm{mg})$ was $k_{s p} / k_{p s} \times \mathrm{P}$. Pools were retrospectively designated EZP $(0-1 \mathrm{~h})$ etc. once the model was established and the rates of turnover of the pools could be estimated.

(c) Composite pool predominating between 1 and $9 d$ post-injection. The size and turnover of the relatively slowly turning over pool, EZP (1-9 d), which dictates plasma ${ }^{70} \mathrm{Zn}$ kinetics between 1 and $9 \mathrm{~d}$ post-injection, was calculated using the methods described by Jackson et al. (1988) and Miller et al. (1991). The specific activity of plasma and urine was plotted semi-logarithmically from days 1-9 and the best-fit straight lines were obtained using the GENSTAT regression program (Payne et al. 1987). The $y$ intercept was used to calculate the size of EZP $(1-9$ d) $($ EZP $(1-9 d)=$ dose/specific activity at time 0$)$ and the half-time calculated from the regression equation.

(d) Mobilizable zinc pool (MBZP). The mobilizable $\mathrm{Zn}$ pool in which the injected ${ }^{70} \mathrm{Zn}$ is diluted was calculated according to the method of Johnson et al. (1991) using the formula:

$$
\operatorname{MBZP}=\frac{\left.3 \cdot 5557^{70} \mathrm{Zn}(\mathrm{ret})\right]}{\mathrm{R}^{70 / 66}(\mathrm{obs})-\mathrm{R}^{70 / 66}(\mathrm{na})},
$$

where $3.555=1 / \mathrm{na}{ }^{66} \mathrm{Zn}(\mathrm{g} / 100 \mathrm{~g})=1 / 0.2813,{ }^{70} \mathrm{Zn}$ (ret) is the amount of ${ }^{70} \mathrm{Zn}$ dose retained in the body $(\mathrm{mg}), \mathrm{R}^{70 / 66}$ (obs) is measured ${ }^{70} \mathrm{Zn}:{ }^{66} \mathrm{Zn}$ ratio in plasma, $\mathrm{R}^{70 / 66}$ (na) is the natural abundance ratio of the two isotopes.

This was derived using the following assumption (Johnson, personal communication):

$$
\mathrm{R}^{70 / 66}(\mathrm{obs})=\frac{{ }^{70} \mathrm{Zn}(\text { ret })+{ }^{70} \mathrm{Zn}(\text { pool })}{{ }^{66} \mathrm{Zn}(\text { pool })},
$$


Table 1. Mean daily intakes of energy, protein, and zinc analysed from duplicate diet collections, excretion of $\mathrm{Zn}$ over $10 \mathrm{~d}$, and mean plasma $\mathrm{Zn}$ concentration $1-2 \mathrm{~h}$ after breakfast for a male $(M)$ and a female $(F)$ subject

\begin{tabular}{|c|c|c|c|c|}
\hline \multirow[t]{2}{*}{ Subject... } & \multicolumn{2}{|c|}{$\mathrm{M}$} & \multicolumn{2}{|c|}{$\mathrm{F}$} \\
\hline & Mean & SD & Mean & SD \\
\hline Energy intake (MJ) & $9 \cdot 22$ & $2 \cdot 60$ & $8 \cdot 58$ & $1 \cdot 15$ \\
\hline Protein intake $(\mathrm{g})$ & 67.9 & 16.8 & $56 \cdot 1$ & 150 \\
\hline $\mathrm{Zn}$ intake $(\mathrm{mg})$ & $10 \cdot 1$ & 1.8 & $7 \cdot 3$ & $2 \cdot 0$ \\
\hline Faecal $\mathrm{Zn}(\mathrm{mg})$ & 112 & & 62 & \\
\hline Urinary $\mathrm{Zn}(\mathrm{mg})$ & 6 & & 5 & \\
\hline $\mathrm{Zn}$ balance $(\mathrm{mg})$ & -17 & & +6 & \\
\hline Plasma $\mathrm{Zn}(\mu \mathrm{g} / \mathrm{ml})$ & $0 \cdot 70$ & 0.09 & 0.60 & 0.04 \\
\hline
\end{tabular}

Table 2. Rate-constants $\left(\mathrm{k} 10^{3} / \mathrm{min}\right)$, and size of plasma pool $\left(E Z P_{a}\right)$ and rapidly exchangeable zinc pool $\left(E Z P_{b}\right)$ derived from deconvolution analysis using the twocompartment model $^{*}$ for a male $(M)$ and a female $(F)$ subject

\begin{tabular}{lcc}
\hline \hline Subject... & $\mathrm{M}$ & $\mathrm{F}$ \\
\hline$k_{b a}\left(10^{3} / \mathrm{min}\right)$ & 42 & 77 \\
$k_{a b}\left(10^{3} / \mathrm{min}\right)$ & 12 & 29 \\
$k_{\text {oa }}\left(10^{3} / \mathrm{min}\right)$ & 42 & 85 \\
$\mathrm{~F}_{\mathrm{ao}}(\mu \mathrm{g} / \mathrm{min})$ & 265 & 277 \\
$\mathrm{EZP}_{\mathrm{a}}(\mathrm{mg})$ & $6 \cdot 4$ & 3.2 \\
$\mathrm{EZP}_{\mathrm{b}}(\mathrm{mg})$ & $22 \cdot 4$ & 8.6 \\
\hline
\end{tabular}

$\mathrm{F}_{\mathrm{a} 0}$, fux into the system.

* For details, see Fig. 1.

where ${ }^{70} \mathrm{Zn}$ (pool) and ${ }^{66} \mathrm{Zn}$ (pool) are amounts (mg) of isotopes naturally occurring in the pool before administration of isotope dose.

\section{Statistical analysis}

Regression analysis on plasma and urine ${ }^{70} \mathrm{Zn}$ specific activity was performed using GENSTAT (Payne et al. 1977). Differences between slopes were tested by a $t$ test, where $t$ is difference in slopes/standard error of difference.

\section{RESULTS}

The mean daily intakes of energy, protein, and $\mathrm{Zn}$, analysed from duplicate diet collections and $\mathrm{Zn}$ balance data, are shown in Table 1 . The negative balance of subject $\mathrm{M}$ is probably due to errors incurred in subdividing faecal collections at the beginning and end of the balance period. The mean daily $\mathrm{Zn}$ intakes for subjects $\mathrm{M}$ and $\mathrm{F}$ were 10.1 (SD 1.8) and $7 \cdot 3$ (SD 2.0) $\mathrm{mg}$ respectively. The mean plasma $\mathrm{Zn}$ concentration measured $1-2 \mathrm{~h}$ after breakfast on each day of the $10 \mathrm{~d}$ balance period is also shown in Table 1 . This was higher for subject $M$ than subject $F$.

The data derived from the two-compartment model using decay data over the first 90 min post-injection are shown in Table 2 and the data from subject $M$ has been used to predict the amount of isotope appearing in the initial pools ( $\mathrm{Qa}$ and $\mathrm{Qb})$ and being removed from the model system (Qc) over 90 min (Fig. 3). 


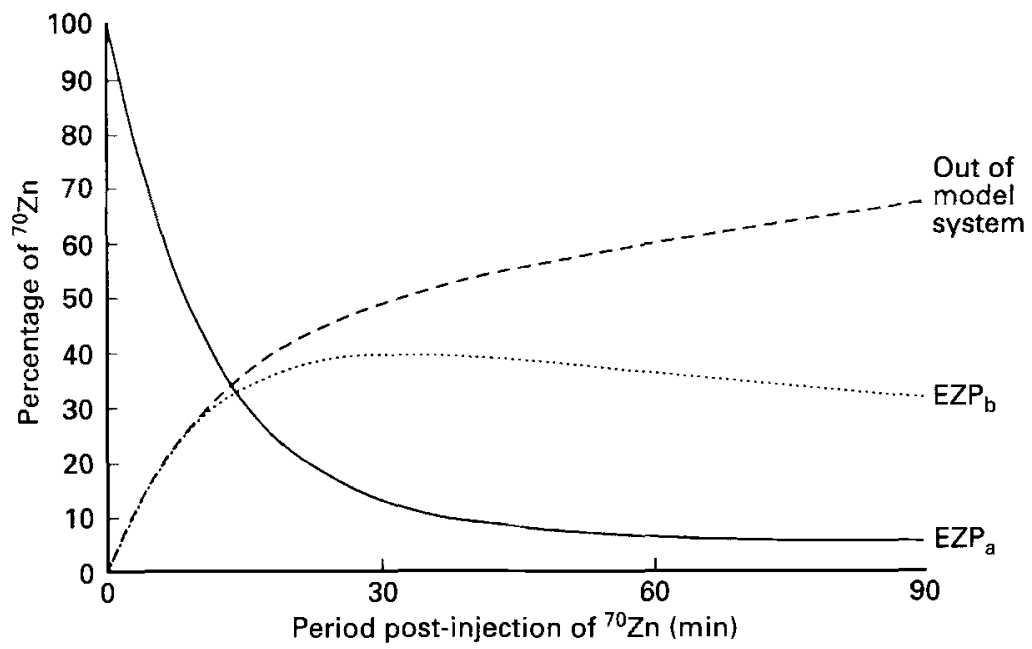

Fig. 3. Short-term $(90 \mathrm{~min})$ kinetic analysis of plasma ${ }^{70} \mathrm{Zn}$ dose in a male subject derived from double-exponential equation obtained from plasma ${ }^{70} \mathrm{Zn}$ decay data. Data are presented as the percentage of the ${ }^{70} \mathrm{Zn}$ dose present in the different pools post-injection. For details of procedures, see pp. 222-223. EZP is the plasma pool, EZP is the rapidly exchangeable pool; for details, see Fig. 1 and pp. 222-225.

Table 3. Rate constants* $\left(\mathrm{k} 10^{3} / \mathrm{min}\right)$, and estimated sizes of rapidly exchangeable ( $E Z P$ $0-1 \mathrm{~h})$ ) and slowly exchangeable EZP $(24 \mathrm{~h})$ zinc pools $(\mathrm{mg})$ using the four-compartment model $\dagger$ for a male $(M)$ and a female $(F)$ subject

\begin{tabular}{lcc}
\hline Subject $\ldots$ & $\mathrm{M}$ & $\mathrm{F}$ \\
\hline$k_{p g}$ & $5 \cdot 0$ & $5 \cdot 0$ \\
$k_{g p}$ & $1 \cdot 0$ & $0 \cdot 5$ \\
$k_{g g}$ & $5 \cdot 0$ & $5 \cdot 0$ \\
$k_{r p}$ & 45 & 35 \\
$k_{p r}$ & 13 & $7 \cdot 5$ \\
$k_{s p}$ & 90 & 95 \\
$k_{p s}$ & $0 \cdot 55$ & $0 \cdot 45$ \\
$k_{u p}$ & $0 \cdot 30$ & $0 \cdot 20$ \\
Plasma (P) fixed pool & $2 \cdot 34$ & $1 \cdot 66$ \\
EZP (0-1 h) pool & $8 \cdot 3$ & $7 \cdot 9$ \\
$t_{\frac{1}{2}}(\mathrm{~h})$ for EZP $(0-1 \mathrm{~h})$ & $0 \cdot 89$ & $1 \cdot 54$ \\
EZP (24 h) pool & 385 & 350 \\
$t_{\frac{1}{2}}(\mathrm{~h})$ for EZP $(24 \mathrm{~h})$ & $21 \cdot 0$ & $25 \cdot 7$ \\
\hline
\end{tabular}

$t \frac{1}{2}$, half-life.

${ }^{*}$ In this study, where ${ }^{70} \mathrm{Zn}$ was injected, the influence of the value of $k_{p g}, k_{g p}$ and $k_{g g}$ on the fit was small and the values given for these rate-constants are, thus, only approximate.

$\dagger$ For details, see Fig. 2.

The 'best fit' data derived from the four-compartment model are shown in Table 3 and the quantity of isotopically-enriched $\mathrm{Zn}(\mu \mathrm{g})$ present in the different pools over $24 \mathrm{~h}$ predicted from the data in Fig. 4. By choosing appropriate values for the rate-constants, the slope of plasma $\mathrm{Zn}$ concentration with time could be closely modelled. The size of pool $\mathrm{P}$ (the total circulating $\mathrm{Zn}$ in plasma) was calculated from the plasma $\mathrm{Zn}$ concentration and total plasma volume using a nomogram of age and body weight (Lentner, 1984). The calculated sizes of EZP $(0-1 \mathrm{~h})$ and EZP $(24 \mathrm{~h})$ pools are dependent, therefore, on the accuracy of this estimate. 


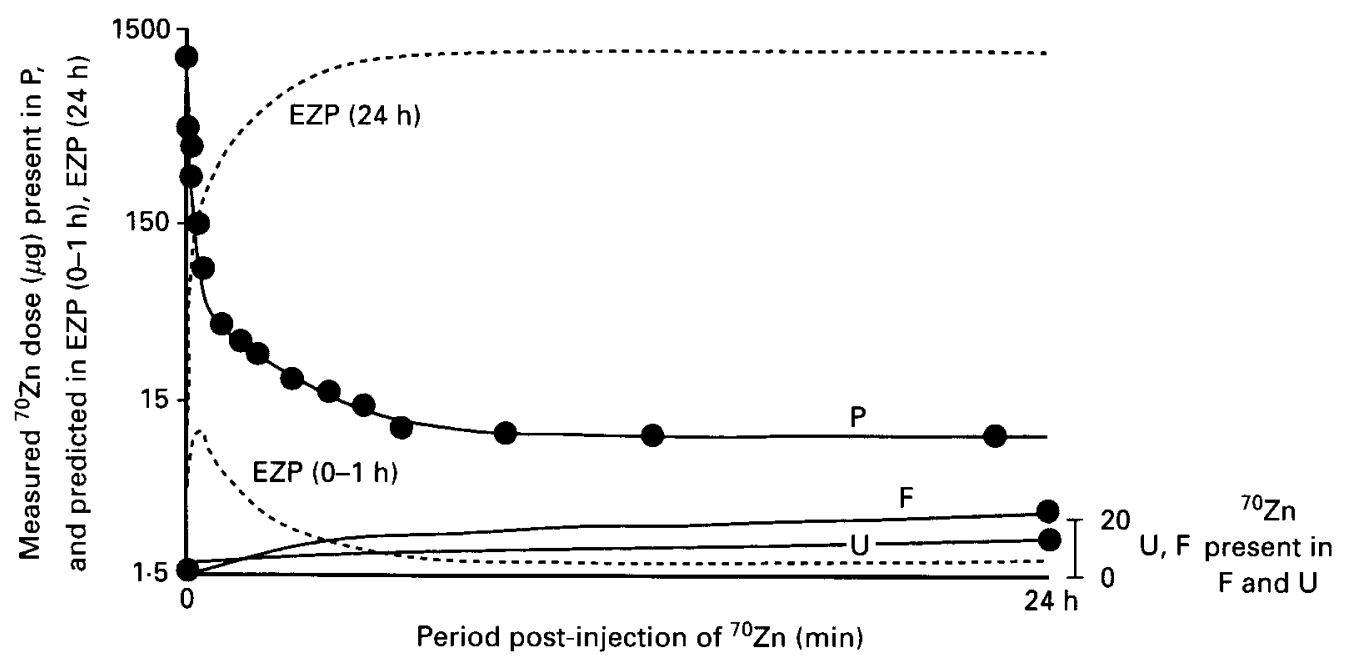

Fig. 4. Medium-term (24 h kinetic analysis of plasma ${ }^{70} \mathrm{Zn}$ in a male subject. Values were obtained using the model shown in Fig. 2. Data are presented on the total amount of ${ }^{70} \mathrm{Zn}$ dose present in the different pools. EZP (0-1 h) is rapidly exchangeable pool, EZP $(24 \mathrm{~h})$ is slowly exchangeable pool, $\mathrm{P}$ is plasma, $\mathrm{U}$ is urinary excretion and $\mathrm{F}$ is faecal excretion.

Table 4. Regression analysis of zinc specific activity $\left(\log _{10}\right)$ in plasma and urine over $9 d$ and calculated size of composite $Z n$ pool $(E Z P(I-9 d))$ for a male $(M)$ and a female $(F)$ subject*

\begin{tabular}{|c|c|c|c|c|}
\hline \multirow[t]{2}{*}{ Subject... } & \multicolumn{2}{|c|}{$\mathbf{M}$} & \multicolumn{2}{|c|}{$\mathrm{F}$} \\
\hline & Plasma & Urine & Plasma & Urine \\
\hline Correlation coefficient & 0.96 & 0.96 & $0 \cdot 79$ & 0.96 \\
\hline Specific activity (day 0 ) & 0.696 & 1.636 & $0 \cdot 123$ & $0 \cdot 320$ \\
\hline Percentage loss of ${ }^{70} \mathrm{Zn} / \mathrm{d} \dagger$ & 11 & 12 & 7 & 11 \\
\hline $\begin{array}{l}\text { Calculated size of EZP }(1-9 \mathrm{~d}) \\
\mathrm{mg}\left({ }^{70} \mathrm{Zn} \text { dose } / \text { specific activity day } 0\right)\end{array}$ & 298 & 127 & 362 & 139 \\
\hline$t_{\frac{1}{2}}(d)$ for EZP $(1-9 d)$ & $5 \cdot 9$ & $5 \cdot 4$ & $9 \cdot 5$ & 5.9 \\
\hline
\end{tabular}

$t_{\frac{1}{2}}$, half life.

$*^{2}$ For details of procedures, see pp. 222-225.

$\dagger$ The percentage loss of ${ }^{70} \mathrm{Zn} / \mathrm{d}$ divided by 100 gives the efflux rate constant $/ \mathrm{d}$ of $\mathrm{Zn}$ from the whole body.

A graph of $\log$ plasma ${ }^{70} \mathrm{Zn}$ dose $v$. time over the first $24 \mathrm{~h}$ post-injection is shown in Fig. 5. The specific activity of the isotope in plasma and urine on days $1-10$ is shown in Fig. 6 . These data were analysed by regression analysis and EZP (1-9 d) calculated from the intercept at 0 time (Table 4). For both subjects there was no significant difference between the slope of the plasma and urine specific activity. However, the urine values were somewhat higher than plasma and, hence, the calculated exchangeable pools very different. The percentage loss of ${ }^{70} \mathrm{Zn}$ dose from the plasma or urine per $\mathrm{d}$ was about $10 \%$ from both subjects. Faecal and urinary losses of administered ${ }^{70} \mathrm{Zn}$ dose were 191.5 and $56.0 \mu \mathrm{g}$ for subject $\mathrm{M}$, and 25.2 and $8 \cdot 3 \mu \mathrm{g}$ for subject $\mathrm{F}$ over the $10 \mathrm{~d}$ balance period.

The mobilizable $\mathrm{Zn}$ pool estimated by the method of Johnson et al. (1991) is shown for days 1-9 in Fig. 7. Using this technique the calculated pool size was greater and varied with time in both subjects, ranging from 285 and $465 \mathrm{mg}$ on day 1 to 593 and $770 \mathrm{mg}$ on day 9 in subjects $M$ and $F$ respectively. 


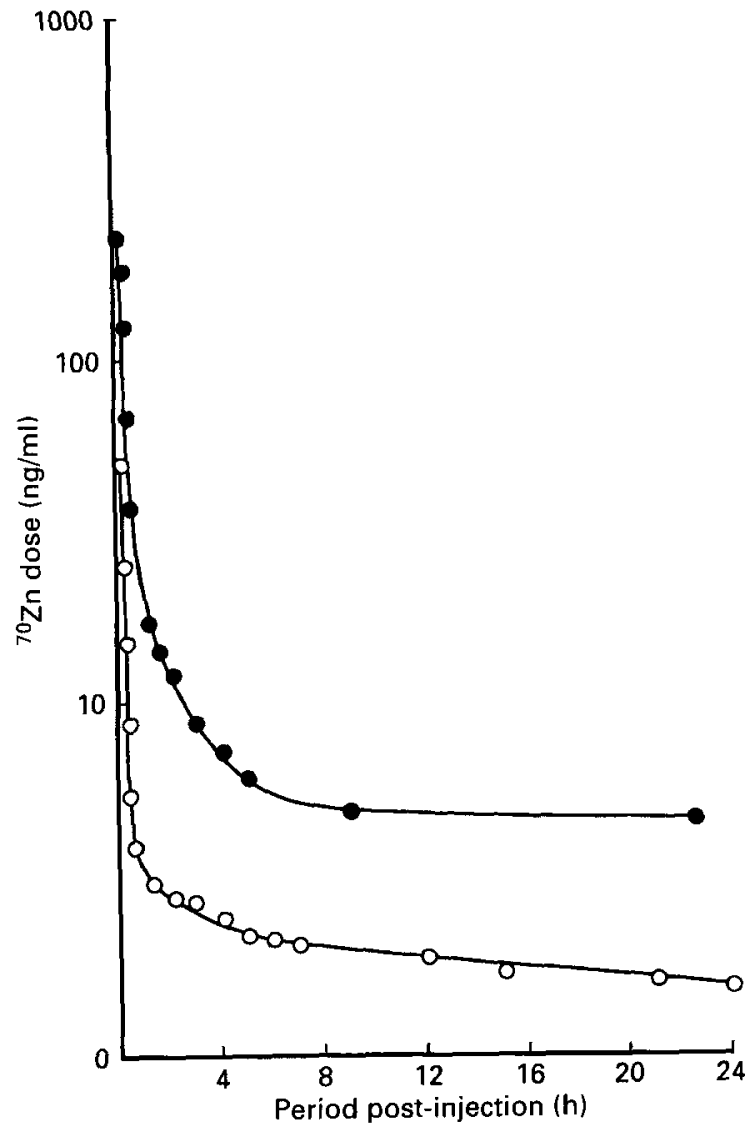

Fig. 5. Log plasma ${ }^{70} \mathrm{Zn}$ dose $(\mathrm{ng} / \mathrm{ml}) v$. time over the first $24 \mathrm{~h}$ post-injection in a male (O) and a female (O) subject injected with ${ }^{70} \mathrm{Zn}$. For details of procedures, see pp. 222--223.

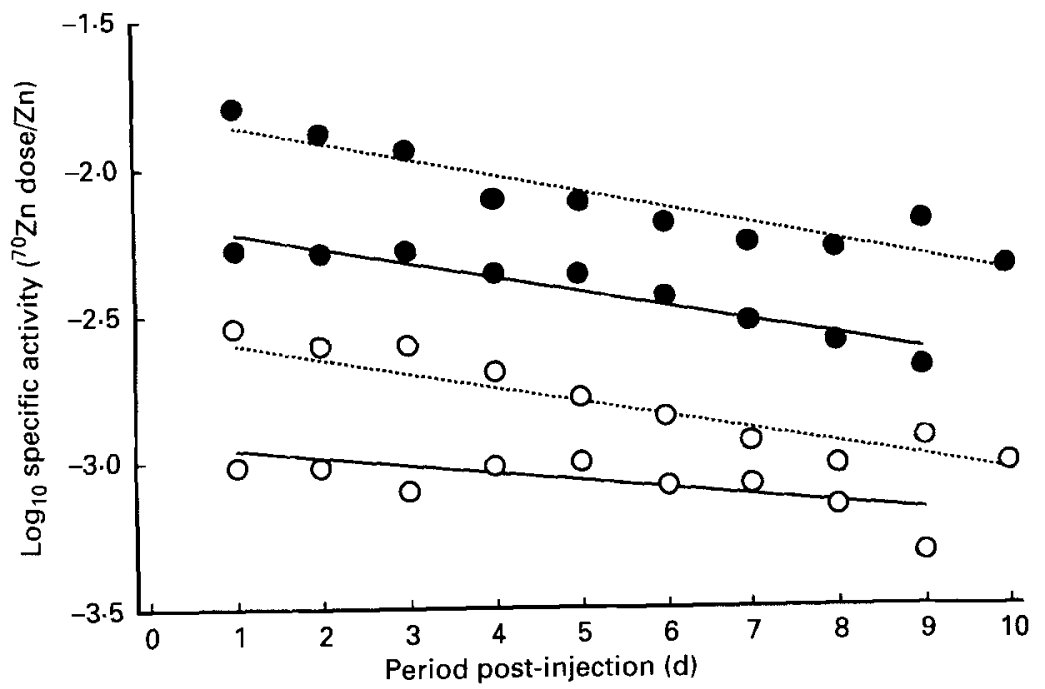

Fig. 6. Plasma (_- ) and urine (---) zinc specific activity $\left(\log _{10}\right) 1-10 \mathrm{~d}$ post-injection in a male $\left(O^{-}\right)$and a female $(O)$ subject. For details of procedures, see pp. $222-223$. 


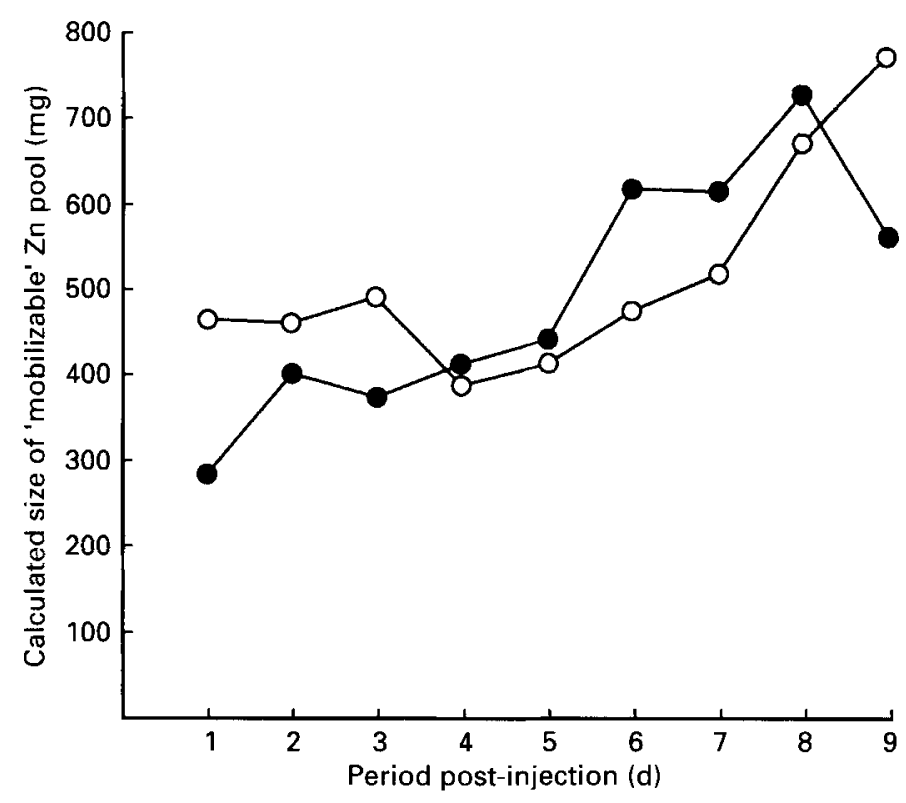

Fig. 7. Mobilizable zinc pool calculated from Johnson et al. (1991) on days 1-9 post-injection, in a male (O and a female (O) subject injected with ${ }^{70} \mathrm{Zn}$. For details of procedures, see pp. 222-223.

\section{DISCUSSION}

Measurements of $\mathrm{Zn}$ intake and functional indices of $\mathrm{Zn}$ status should provide information needed to investigate $\mathrm{Zn}$ requirements and to assess the adequacy of various diets in different subgroups of the population. However, the lack of sensitive and specific indices of $\mathrm{Zn}$ status has initiated a search for alternative techniques to study $\mathrm{Zn}$ requirements.

Foster et al. (1979) describe a kinetic model developed to study $\mathrm{Zn}$ metabolism in humans using the radio-isotope ${ }^{69} \mathrm{Zn}$. They identified rapid and slow exchange phases between plasma and liver and between plasma and erythrocytes but the tracer data were only able to account for $10 \%$ of the total body $\mathrm{Zn}$, the remaining $90 \%$ being in tissue whose kinetics are too slow to be resolved within the $5 \mathrm{~d}$ period of study. Radioisotopes offer clear advantages over stable isotopes, for example the measurement of $\mathrm{Zn}$ isotope in different regions of the body using external counters. As in our study, Foster et al. (1979) found that there was a rapid initial flow of isotope out of the plasma, the site being identified as the liver. A two-compartment system, one rapid and one slow pathway for erythrocytes and liver, was included in their model. Although we did not measure erythrocyte ${ }^{70} \mathrm{Zn}$, we analysed the final blood samples and found the erythrocyte enrichment to be $0.05 \%$ in subject $F$ and $0.44 \%$ in subject $M$. The leucocytes were not measurably enriched.

The original kinetic modelling studies used radio- $\mathrm{Zn}$. However, the current move away from human studies employing radioactive substances, because of concern about possible hazards from ionizing radiation, has led to the development of alternative techniques using stable isotopes (Miller et al. 1991). These are more costly, their analysis more exacting and larger quantities are required than with radioisotopes; their main advantage is safety, but in addition there is sample stability and the ability to perform multiple-labelling studies. However, stable isotope studies will not provide the type of detailed information necessary to derive complex models such as that used by Wastney et al. (1986) and, therefore, it is necessary to develop suitable techniques for the analysis of stable isotope decay data. The 
nature of the information available dictates that suitable models will be relatively simple and we have examined, therefore, four possible ways of interpreting ${ }^{70} \mathrm{Zn}$ decay data to determine the relevance and reliability of the different techniques.

The four techniques examined are not exclusive and could have complementary roles in the interpretation of data. The short-term technique of deconvolution analysis based on the method described by Shipley \& Clark (1972) assumes that the initial kinetics are dictated only by two rapidly exchanging compartments of body $\mathrm{Zn}$ (animal studies suggest that these are the plasma $\left(\mathrm{EZP}_{\mathrm{a}}\right)$ and a discrete pool of the liver $\left.\mathrm{Zn}\left(\mathrm{EZP}_{\mathrm{b}}\right)\right)$. This is supported by the close 'fit' of the decay data over $90 \mathrm{~min}$ to a two-component exponential decay curve (Lowe et al. 1992) but is almost certainly an over-simplification of the true picture. One advantage of this technique is that the pool with which the isotope initially exchanges is calculated from the decay data rather than fixed and, hence, the procedure should be capable of detecting an expansion or contraction of this pool, but it would not provide any access to $\mathrm{Zn}$ pools which are relatively slowly exchanging with plasma $\mathrm{Zn}$, even if these varied greatly from normal.

The four-compartment model based on data obtained between 0 and $24 \mathrm{~h}$ provides an extension of the model described and in an ideal situation should provide directly comparable data for some of the calculated pool sizes and rate-constants. A comparison of Figs. 1 and 2 and Figs. 3 and 4 illustrates that EZP $\mathrm{a}_{\mathrm{a}}$ and EZP $\mathrm{P}_{\mathrm{b}}$ in Fig. 1 are the same as $\mathrm{P}$ and EZP $(0-1 \mathrm{~h})$ in Fig. 2, while the fractional flux of $\mathrm{Zn}$ out of the system in Fig. $1\left(k_{o a}\right)$ should incorporate $k_{s p}, k_{u p}$ and $k_{g p}$ from Fig. 2 . The underlying concept behind the $\mathrm{Zn}$ models is different, however, in that the size of the plasma pool $(\mathrm{P})$ is fixed in the fourcompartment model and, hence, dictates the sizes of the other major pools EZP $(0-1 \mathrm{~h})$ and EZP ( $24 \mathrm{~h})$. In normal subjects $\mathrm{P}$ can probably be fixed with reasonable accuracy knowing the plasma $\mathrm{Zn}$ concentrations and an estimate of total plasma volume from body size, but will be subject to artefact if changes in plasma volume occur. However, this model does take into account more of the known physiological movements of $\mathrm{Zn}$, although it should be emphasized that the rate-constants are overall rate-constants and do not differentiate between free and bound $\mathrm{Zn}$ in plasma and tissues. The fit of the data to this model was very insensitive to variations in $k_{p g}, k_{g p}$, and $k_{g g}$, hence the major differences between the two models are likely to be the allowance for two-way movement of $\mathrm{Zn}$ between EZP (24 h) and $\mathrm{P}$.

Direct comparison of the sizes of EZP $\mathrm{F}_{\mathrm{b}}$ (Table 2) and EZP ( $\left.0-1 \mathrm{~h}\right)($ Table 3$)$ shows that although they are of similar magnitude they differ to some extent for one subject. One reason for this is the difference in the calculated values for $\operatorname{EZP}_{a}$ (Table 2) and the fixed level of $P$ (Table 3 ) although this cannot provide all of the explanation. The fractional movement of $\mathrm{Zn}$ from EZP $\mathrm{P}_{\mathrm{a}}$ or the plasma into the second pool (EZP $\mathrm{P}_{\mathrm{b}}$ and EZP $(0-1 \mathrm{~h})$ respectively), i.e. $k_{b a}$ and $k_{r p}$, agree reasonably well, but the reverse fluxes $\left(k_{a b}\right.$ and $\left.k_{p r}\right)$ only agree well for one subject.

The four-compartment model also indicates the existence of a relatively large pool of $\mathrm{Zn}$ (385 and $350 \mathrm{mg}$ for subjects $\mathrm{M}$ and $\mathrm{F}$ respectively) with a half-life of about 21-25 $\mathrm{h}$ EZP $(24 \mathrm{~h})$. A pool of a similar size was calculated from the plasma ${ }^{70} \mathrm{Zn}$ decay between 1 and $9 \mathrm{~d}$ post-injection (Fig. 6 and Table 4), but the turnover of this pool was considerably slower ( $t_{\frac{1}{2}} 5.9$ and $9.5 \mathrm{~d}$ ) suggesting that these cannot represent the same pool. Both Jackson et al. (1988) and Miller et al. (1991) have previously studied a putative pool exchanging over $9 \mathrm{~d}$ and our data are in reasonable agreement with their reported values.

The 'mobilizable' Zn pool defined by Johnson et al. (1991) is equivalent to the concept of Se 'apparent body pool size' described by Janghorbani et al. (1984). In theory, its value should reach the amount of the element contained in the body, after a long period of time. However, the method of calculation used by Johnson et al. (1991) assumes that all the 
isotope retained within the body is contained within a single pool in equilibrium with plasma $\mathrm{Zn}$. This appears to be a gross over-simplification of the actual situation and the data in Fig. 7 indicate that the values obtained are inconsistent with time and do not agree with values reported for any of the other four techniques. The validity of this technique is, therefore, open to question.

The dose of stable isotope administered must be high enough to cause measurable enrichment yet should not alter the system in any way. Bearing this in mind, we chose two levels of $\mathrm{Zn}$ to cover what we considered to be the workable range. In normal subjects only about $2-8 \%$ of plasma $\mathrm{Zn}$ is ultrafilterable as most of it is bound to protein. Yunice et al. (1978) found that when dogs are infused with $40 \mathrm{mg} \mathrm{Zn}$ (as $\mathrm{ZnSO}_{4}$ ), thereby causing a 40 fold increase in total plasma $\mathrm{Zn}$, there is no measurable increase in plasma ultrafilterable $\mathrm{Zn}$ concentration and only a 3 -fold increase in $\mathrm{Zn}$ excretion. Thus, there should have been no perturbation of $\mathrm{Zn}$ metabolism in our study, even at the highest dose of $2.078 \mathrm{mg}{ }^{70} \mathrm{Zn}$ enriched $\mathrm{Zn}$.

The use of urine instead of plasma to follow $\mathrm{Zn}$ isotope kinetics is an attractive proposition. The slopes of plasma and urine in both subjects were not significantly different (Fig. 3, Table 4), although the lines were markedly offset giving rise to a difference in size of calculated slowly exchangeable pool. Friel et al. (1992) also found similar enrichment in plasma and urine following oral and intravenous doses of $\mathrm{Zn}$ stable isotopes, although their data were not subjected to statistical evaluation. Since the difference between plasma and urine specific activity was too large to be explained in terms of the time interval between glomerular filtration and micturition we considered other possibilities. Initially we thought that the disparity might lie in the way the data were handled. For the purposes of this part of the study we assumed a system in which the loss of $\mathrm{Zn}$ from the system followed one exponential over the period from 1 to $9 \mathrm{~d}$, but there is a suggestion from the plasma data (subject $\mathrm{M}$ ) in Fig. 6 that this is an oversimplification and that the $9 \mathrm{~d}$ data could be split at day 3 to incorporate another exponential. This might then change the slopes and, hence, calculated pool sizes. However, the enrichment of plasma samples after the first $24 \mathrm{~h}$ for subject $\mathrm{F}$ was not great enough to support a more detailed analysis of the data, although this is an objective of future work in this area.

Another, perhaps more obvious, explanation is an error in the assumption that all the plasma $\mathrm{Zn}$ exchanged with the infused ${ }^{70} \mathrm{Zn}$. Chesters \& Will (1981) demonstrated that onethird of plasma $\mathrm{Zn}$ is firmly bound to $\alpha_{2}$-macroglobulin, and two-thirds more loosely bound to albumin. In a pilot experiment, blood was taken from the subjects, the plasma removed immediately, $0 \cdot 5 \mu \mathrm{Ci}^{65} \mathrm{Zn}$ (virtually carrier-free, Amersham International, Bucks.) added and after $1 \mathrm{~h}$ equilibration the plasma dialysed at $37^{\circ}$ against $9 \mathrm{~g} \mathrm{NaCl} / 1$ (molecular weight cut-off 10-12000) for $0.5 \mathrm{~h}$. In both subjects the specific activity of the plasma in the sac was considerably less than that in the dialysate, indicating the presence of a nonexchangeable fraction. We intend to carry out further work to investigate the reasons for the observed differences between plasma and urine. However, if, as we suggest, some of the $\mathrm{Zn}$ in plasma is non-exchangeable, then urine may provide a more accurate estimate of the size of the exchangeable pool of $\mathrm{Zn}$ in the body than plasma. If such a situation should eventually be proved to exist then this will also have significant effects on the calculated sizes of exchangeable $\mathrm{Zn}$ pools (Tables 2 and 3) and the fluxes between the pools. Discussion of this is not taken further here because of uncertainties concerning the presence of non-exchanging $\mathrm{Zn}$ in plasma. It is of interest to note, however, that the EZP (1-9 d) calculated from urine, 127 and $139 \mathrm{mg}$ in subjects $\mathrm{M}$ and $\mathrm{F}$ respectively, was very close to the value of $108 \mathrm{mg}$ calculated by Wastney et al. (1986) to be the total sum of rapid compartments in the model used to fit longer-term ( $>2 \mathrm{~d}$ ) kinetics of $\mathrm{Zn}$ metabolism following a dose of ${ }^{65} \mathrm{Zn}$. 
This study has demonstrated the feasibility of using an intravenous infusion of ${ }^{70} \mathrm{Zn}$ stable isotope to study $\mathrm{Zn}$ metabolism using doses between 0.445 and $2.078 \mathrm{mg} \mathrm{Zn}$. Kinetic modelling can be used to predict body pool sizes. In addition to the plasma $\mathrm{Zn}$ pool there appears to be a rapidly-exchangeable pool, EZP $/ \mathrm{b} / \mathrm{EZP}(0-1 \mathrm{~h})$ of less than $25 \mathrm{mg}$ and one or more slower exchanging pools calculated from plasma data to be approximately $300 \mathrm{mg}$, but about half this when calculated from urine data. Further research is needed to investigate the differences between plasma and urine specific activity, to refine the model and to test whether the pool sizes are sensitive to dietary and/or physiological change. As it stands the four-compartment model could be used to investigate $\mathrm{Zn}$ absorption. However, it may be necessary to modify the number of gut compartments and perhaps to allow for differences in the rate-constants in different parts of the gut. Preliminary data indicate that EZP ${ }_{\mathrm{a}}, \mathrm{EZP}_{\mathrm{b}}$ (Lowe et al. 1991) and EZP (1-9 $)$ (Miller et al. 1991) are likely to vary with changes in dietary $\mathrm{Zn}$ intake, although this has not been examined in a definitive manner. We believe that analysis of body $\mathrm{Zn}$ pools by a system such as those considered here may provide a useful means of assessing $\mathrm{Zn}$ status and, hence, to determine dietary $\mathrm{Zn}$ requirements.

The authors would like to thank Dr Hugh Kennedy for administering the ${ }^{70} \mathrm{Zn}$ injections and the Wellcome Trust for financial support (M.J.J.).

\section{REFERENCES}

Aggett, P. J. (1991). Diagnostic value of measurements for trace elements. in Infantile Nutrition-An Update, pp. 53-65, [R. Di Toro, editor]. Basel: Karger.

Chesters, J. K. \& Will, M. (1981). Zinc transport proteins in plasma. British Joumal of Nutrition 46, 111-118.

Eagles, J., Fairweather-Tait, S. J., Portwood, D. E., Self, R., Gotz, A. \& Heumann, G. (1989). Comparison of fast atom bombardment mass spectrometry and thermal ionization quadrupole mass spectrometry for the measurement of zinc absorption in human nutrition studies. Analytical Chemistry 61, 1023-1025.

Fairweather-Tait, S. J., Fox, T. E., Wharf, S. G., Eagles, J. \& Kennedy, H. (1992). Zinc absorption in adult men from a chicken sandwich made with white or wholemeal bread, measured by a double-label stable-isotope technique. British Journal of Nutrition 67, 411-419.

Foster, D. M., Aamodt, R. L., Henkin, R. I. \& Berman, M. (1979). Zine metabolism in humans: a kinetic model. American Journal of Physiology 237, R340-R349.

Fox, T. E., Fairweather-Tait, S. J., Eagles, J. \& Wharf, S. G. (1991). Intrinsic labelling of different foods with stable isotopes of zinc $\left({ }^{67} \mathrm{Zn}\right)$ for use in bioavailability studies. British Journal of Nutrition 66, 57-63.

Friel, J. K., Naake, V. L., Miller, L. V., Fennessey, P. V. \& Hambidge, K. M. (1992). The analysis of stable isotopes in urine to determine the fractional absorption of zinc. American Journal of Clinical Nutrition $\mathbf{5 5}$, $473-477$.

Garretts, M. \& Molokhia, M. (1977). Acrodermatitis enteropathica without hypozincaemia. Journal of Pediatrics 91, $492-494$.

Gibson, R. S. (1989). Assessment of trace element status in humans. Progress in Food and Nutrition Science 13, $67-111$.

Jackson, M. J. (1989). Physiology of zinc: general aspects. In Zinc in Human Biology, pp. 1-14, [C. F. Milis, editor]. London: Springer-Verlag.

Jackson, M. J., Giugliano, R., Giugliano, L. G., Oliveira, E. F., Shrimpton, R. \& Swainbank, I. G. (1988). Stable isotope metabolic studies of zinc nutrition in slum-dwelling lactating women in the Amazon valley. British Joumal of Nutrition 59, 193-203.

Janghorbani, M., Kasper, L. J. \& Young, V. R. (1984). Dynamics of selenite metabolism in young men: studies with the stable tracer method. American Journal of Clinical Nutrition 40, 208-218.

Johnson, P. E., Vanderpool, R. A., Milne, S. K., Mahajan, S. K., Prasad, A. S. \& Mullen, L. K. (1991). Stable isotope studies of experimental zinc deficiency in adult men. In Trace Elements in Man and Animals, vol. 7 , pp. 4-6-4-7, [B. Momcilovic, editor]. Zagreb: IMI.

Lentner, C. (1984). Geigy Scientific Tables, p. 66, Basle: Ciba-Geigy.

Lowe, N. M., Bremner, 1. \& Jackson, M. J. (1991). Plasma ${ }^{65} \mathrm{Zn}$ kinetics in the rat. British Journal of Nutrition 65 , 445-455.

Lowe, N. M., Rhodes, J. M., Green, A. \& Jackson, M. J. (1992). Stable isotope studies of short-term plasma zinc kinetics in normal human subjects. Proceedings of Nutrition Society 51, 59A.

Miller, L. V., Fennessey, P. V., Friel, J. K., Hong, Z., Naake, V. L., Westcott, J. L. \& Hambidge, K. M. (1991). 
Measurement of an exchangeable pool of zinc by analysis of stable isotope tracer in plasma and urine. $F A S E B$ Journal 5, A921.

Payne, R. W., Lane, P. W., Ainsley, A. E., Bicknell, K. E., Digby, P. G. N., Harding, S. A., Leech, P. K., Simpson, H. R., Todd, A. D., Verrier, P. J., White, R. P., Gower, J. C., Tunnicliffe-Wilson, G. \& Patterson, L. J. (1987). GENSTAT 5 Reference Manual. Oxford: Clarendon Press.

Shipley, R. A. \& Clark, R. E. (1972). Tracer Methods for 'in vivo' Kinetics. New York: Academic Press.

Tomlinson, J., Bannister, S. C., Croghan, P. C. \& Duncan, G. (1991). Analysis of rat lens ${ }^{45} \mathrm{Ca}^{2+}$ fluxes: evidence for $\mathrm{Na}^{+}-\mathrm{Ca}^{2+}$ exchange. Experimental Eye Research 52, 619-627.

Turnlund, J. R. \& Keyes, W. R. (1990). Automated analysis of stable isotopes of zinc, copper, iron, calcium and magnesium by thermal ionisation mass spectrometry using double isotope dilution for tracer studies in humans. Journal of Micronutrient Analysis 7, 117-145.

Wastney, M. E., Aamodt, R. L., Rumble, W. F. \& Henkin, R. I. (1986). Kinetic analysis of zinc metabolism and its regulation in normal humans. American Journal of Physiology 251, R398-R408.

Yunice, A. A., King, R. W., Kraikitpanitch, S., Haygood, C. C. \& Lindeman, R. D. (1978). Urinary zinc excretion following infusions of zinc sulphate, cysteine, histidine, or glycine. American Journal of Physiology 235, F40-F45.

\section{APPENDIX}

The four-compartment model shows the compartments used in the analysis and the rateconstants that define the fluxes between them. There are three gut compartments that might, but not necessarily, equate to stomach, small intestine and large intestine.

The following equations have been solved simultaneously in the program. The symbols for the compartments define the quantities in the compartments and $\mathrm{G}$, gut; $\mathrm{P}$, plasma; $\mathrm{F}$, faecal excretion; R, rapidly-mobilizable pool; S, slowly-mobilizable pool; U, urinary excretion.

$$
\begin{gathered}
\frac{d G_{1}}{d t}=\frac{k_{g p} P}{3}-k_{p g} G_{1}-3 k_{g g} G_{1}, \\
\frac{d G_{2}}{d t}=\frac{k_{g p} P}{3}-k_{p g} G_{2}-3 k_{g g}\left(G_{2}-G_{1}\right), \\
\frac{d G_{3}}{d t}=\frac{k_{g p} P}{3}-k_{p g} G_{3}-3 k_{g g}\left(G_{3}-G_{2}\right), \\
\frac{d F}{d t}=3 k_{g g} G_{3}, \\
\frac{d P}{d t}=k_{p g}\left(G_{1}+G_{2}+G_{3}\right)+k_{p r} R+k_{p s} S-\left(k_{g p}+k_{r p}+k_{s p}+k_{u p}\right) P, \\
\frac{d E Z P(0-1 h)}{d t}=k_{r p} P-k_{p r} E Z P(0-1 h), \\
\frac{d E Z P(24 h)}{d t}=k_{s p} P-k_{p s} E Z P(24 h), \\
\frac{d U}{d t}=k_{u p} P .
\end{gathered}
$$

